\title{
Water Distribution and Silt Clogging in the Strong-Seepage Zone Infiltration Process of Yufuhe River from Yellow River Water Based on the Two-Dimensional Sand Tank Model
}

\author{
Weidong Zhao ${ }^{1}$, Weiping Wang ${ }^{1, *}$, Shuai Liu ${ }^{2}$, Shisong $Q u^{1}$, Xiuxiu Sun ${ }^{1}$ and Yujie Meng ${ }^{1}$ \\ 1 School of Water Conservancy and Environment, University of Jinan, Jinan 250022, China; \\ zhaowdbluesky1992@126.com (W.Z.); stu_quss@ujn.edu.cn (S.Q.); sunxiuxiusxx@126.com (X.S.); \\ meng199803@126.com (Y.M.) \\ 2 Shandong Xinhui Construction Group Co., Ltd., Dongying 257091, China; 15053130651@163.com \\ * Correspondence: stu_wangwp@ujn.edu.cn; Tel.: +86-139-5316-2318
}

check for

updates

Citation: Zhao, W.; Wang, W.; Liu, S.; Qu, S.; Sun, X.; Meng, Y. Water Distribution and Silt Clogging in the Strong-Seepage Zone Infiltration Process of Yufuhe River from Yellow River Water Based on the TwoDimensional Sand Tank Model. Water 2021, 13, 1200. https://doi.org/ 10.3390/w13091200

Academic Editor: Juan José Durán

Received: 18 March 2021

Accepted: 22 April 2021

Published: 26 April 2021

Publisher's Note: MDPI stays neutral with regard to jurisdictional claims in published maps and institutional affiliations.

Copyright: (c) 2021 by the authors. Licensee MDPI, Basel, Switzerland. This article is an open access article distributed under the terms and conditions of the Creative Commons Attribution (CC BY) license (https:// creativecommons.org/licenses/by/ $4.0 /)$.

\begin{abstract}
A two-dimensional sand tank experiment was designed to explore the mechanism of water distribution and silt clogging of Yellow River water whilst replenishing groundwater in 'open window' reach of the piedmont river and strong seepage area consisting of a gravel and karst layer from top to bottom. Water released through the reach was divided into surface, pore and fracture karst water, of which karst water was an effective recharge from the surface water. A reasonable released water plan is necessary in recharging to avoid invalid recharge. The karst water accounted for $60-70 \%$ of the amount of water released before clogging, and this value was reduced to approximately $10-20 \%$ whilst a thin clay layer formed from suspended particles on the surface layer of the medium after clogging. The removal rate of suspended solids along vertical and lateral directions in the medium can reach over $96 \%$. The retained amount of suspended particles was mainly distributed on the surface and upper layer region of the medium. A rubber dam can improve effective infiltration whilst promoting suspended solid deposition in the medium. The fitting degree of the numerical simulation and measured results was above 0.9 , which proves the reliability of the sand tank model results.
\end{abstract}

Keywords: sand tank experiment; managed aquifer recharge; piedmont plain channel infiltration; suspended particle clogging; Yellow River water

\section{Introduction}

A series of groundwater recharge projects has been established in the Yufuhe Basin in the southwest of Jinan City to solve the contradiction between water supply and spring preservation caused by the rapid increase in water demand during the development of Jinan [1]. Managed aquifer recharge (MAR) is the intentional recharge of water to an aquifer for subsequent recovery and environmental benefit [2]. MAR is widely applied in Europe and America, and especially Australia, where relevant national guidelines have been issued to ensure the efficient operation of MAR projects for groundwater recovery because of its multiple positive effects [3,4]. The continuous occurrence of clogging in the infiltration medium during the period of groundwater recharge is due to the use of surface water, reclaimed water, urban stormwater runoff, etc. as source water can seriously impact the efficiency of the recharge process [5]. Physical clogging in the groundwater recharge system is common and unavoidable. Artificial recharge projects in Maryland, USA involved 207 stormwater underground water projects in 1986, of which 30\% operated for less than 2 years before cancellation due to clogging. The scrap rate was above 50\% after six years. These phenomena illustrated that short operational lives of infiltration systems are mainly caused by aquifer clogging. Aquifer clogging primarily includes physical, chemical and biological clogging. Notably, physical clogging caused by suspended particles can easily occur in all clogging types. Physical clogging on the surface and at the 
upper layer of the porous medium is related to characteristics of the infiltration medium, concentration of suspended solids, filling of gas and pressure and quality of recharge water. Clogging problems caused by several factors are typically investigated through laboratory experiments and field observation [6-8]. Velocity of recharge water affects the deposition of suspended particles in the aquifer. Critical velocity exists in the recharge process, and mobility of particles causes the aquifer clogging to be divided into two types because of the relation between the critical velocity and injection speed. The deposition rate of suspended particles decreased when the recharge velocity was higher than the critical velocity. On the contrary, an increase in suspended solids deposition rates was observed [9]. The clogging degree of the aquifer was also affected by the size and concentration of suspended particles in the recharge water. The deposition of suspended particles with a maximum diameter of $6 \mu \mathrm{m}$ in the medium was the main cause of physical clogging [10]. The risk of causing aquifer blockage is reduced sharply when the concentration of suspended particles in the recharge water is less than $25 \mathrm{mg} / \mathrm{L}$. The influence of exogenous and endogenous particles on the recharge process of an aqueous medium must be considered and serious clogging was caused by high concentrations of exogenous solids. Meanwhile, the accumulation and mobility of endogenous particles were also promoted by high exogenous particle concentrations [7].

Studies on suspended particle clogging have been focused on one-dimensional conditions. The groundwater recharge of the piedmont river channel is different from that of the plain, which is affected by the slope of the mountain front channel, and it has both runoff and infiltration processes. However, ordinary sand column experiments are not suitable to study this scientific problem. Thus, the mechanism of water distribution and silt clogging must be explored using a two-dimensional sand tank experiment in the piedmont river channel. In this paper, a two-dimensional sand tank experiment was designed to simulate the water distribution and sediment clogging process in the strong seepage zone of the Yufuhe River under special hydrogeological conditions.

\section{Materials and Methods}

\subsection{Study Area and Hydrogeological Conditions}

Yufuhe River Basin is located in the west of Jinan City, China (Figure 1). It has a temperate continental climate with an average annual precipitation of $600 \mathrm{~mm}$. The Yufuhe River originates from the southern mountainous area of Jinan City, with a total length of $41 \mathrm{~km}$, basin area of $827 \mathrm{~km}^{2}$, and finally flows into the Yellow River in the western suburbs of Jinan City. Yufuhe River Basin belongs to a piedmont plain area, the terrain is high in the south and low in the north. The study area is located between Dongkoma Village and Cuima Village in the Yufuhe River Basin upstream area (Figure 1). The lithology of the mountains on both sides of the river is dominated by Cambrian and Ordovician limestone, which is a typical karst landform. The slope of the river channel is $1 / 200-1 / 500$. In the study region, the geological structure of this river channel is a Quaternary sand gravel layer and Cambrian Zhangxia limestone from bottom to top (Figure 2). The thickness of the sand gravel layer is 7-30 m, which gradually thickens from upstream to downstream. The aquifer is rich in loose pore phreatic water, mainly from river seepage and precipitation recharge. The thickness of Zhangxia limestone is 132-234 m. Karst fissures have developed, mainly with 2 $6 \mathrm{~mm}$ dissolution pores, caverns, and fissures with a pore size of about $1 \mathrm{~cm}$. The main groundwater type of the aquifer is carbonate fissure karst water, from the supply of pore water in the upper sand gravel layer. There is impermeable Xuzhuang Formation shale under the sand gravel layer in the upstream channel of the study area. In the downstream channel, the impermeable shale of the Changshan Formation is hidden under the Quaternary sand and gravel layer, forming an impermeable boundary. Additionally, the Zhangxia limestone has a good hydraulic relationship with Ordovician limestone in the downstream reaches through the Chaomidain fracture with strong permeability. Thus, this section of study area is also a typical "open window" river channel, with a strong hydraulic connection between the sand gravel and Zhangxia limestone layer. The river 
flows through the study area, and a large amount of river water seepage occurs and surface water is converted into groundwater. After passing through the sand gravel layer and the Zhangxia limestone, the groundwater continues to flow downstream through the Chaomidian fracture, and is finally discharged by spring water and artificial mining. The Yufuhe River is a seasonal river.

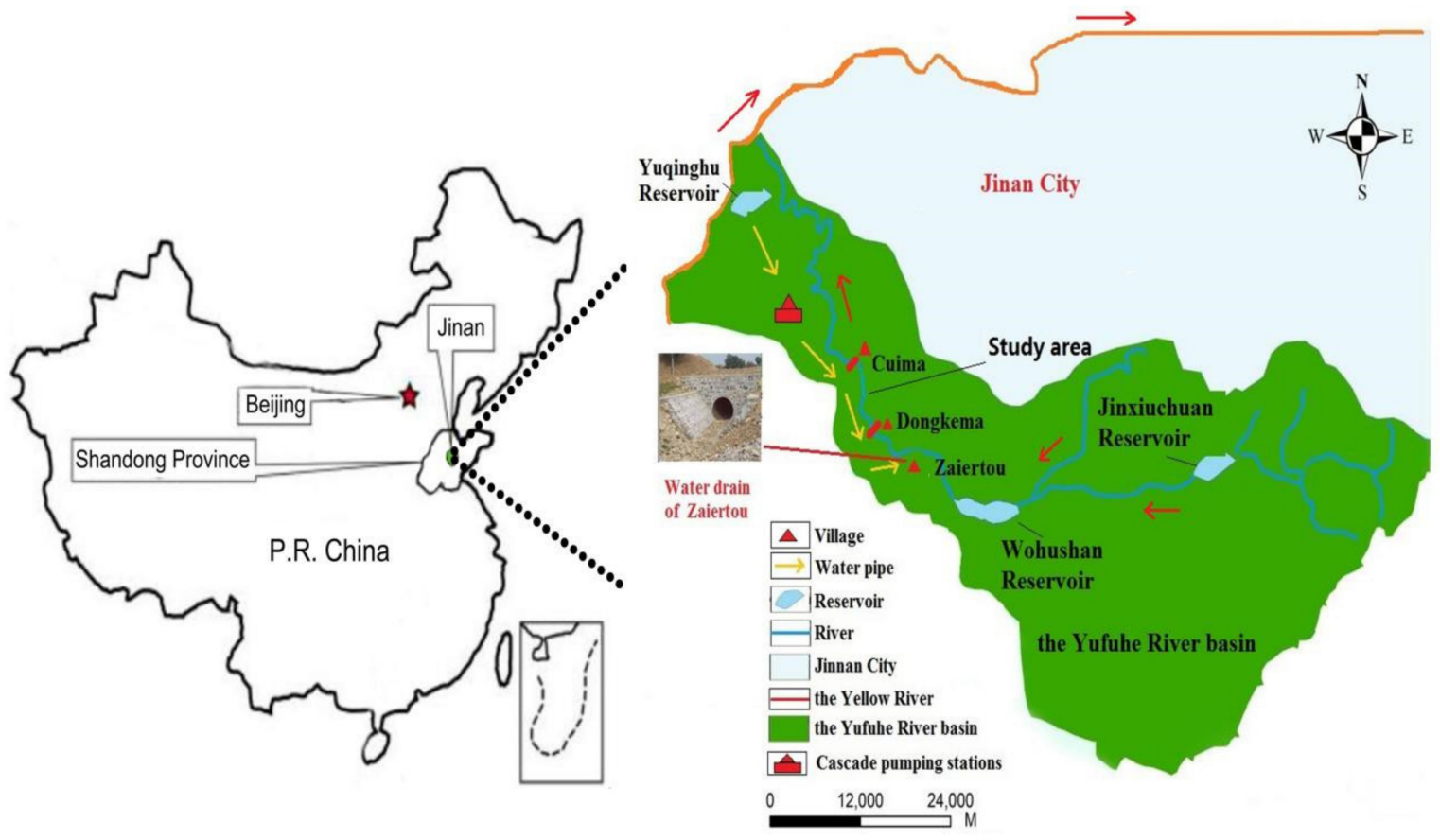

Figure 1. Location map of the study region.

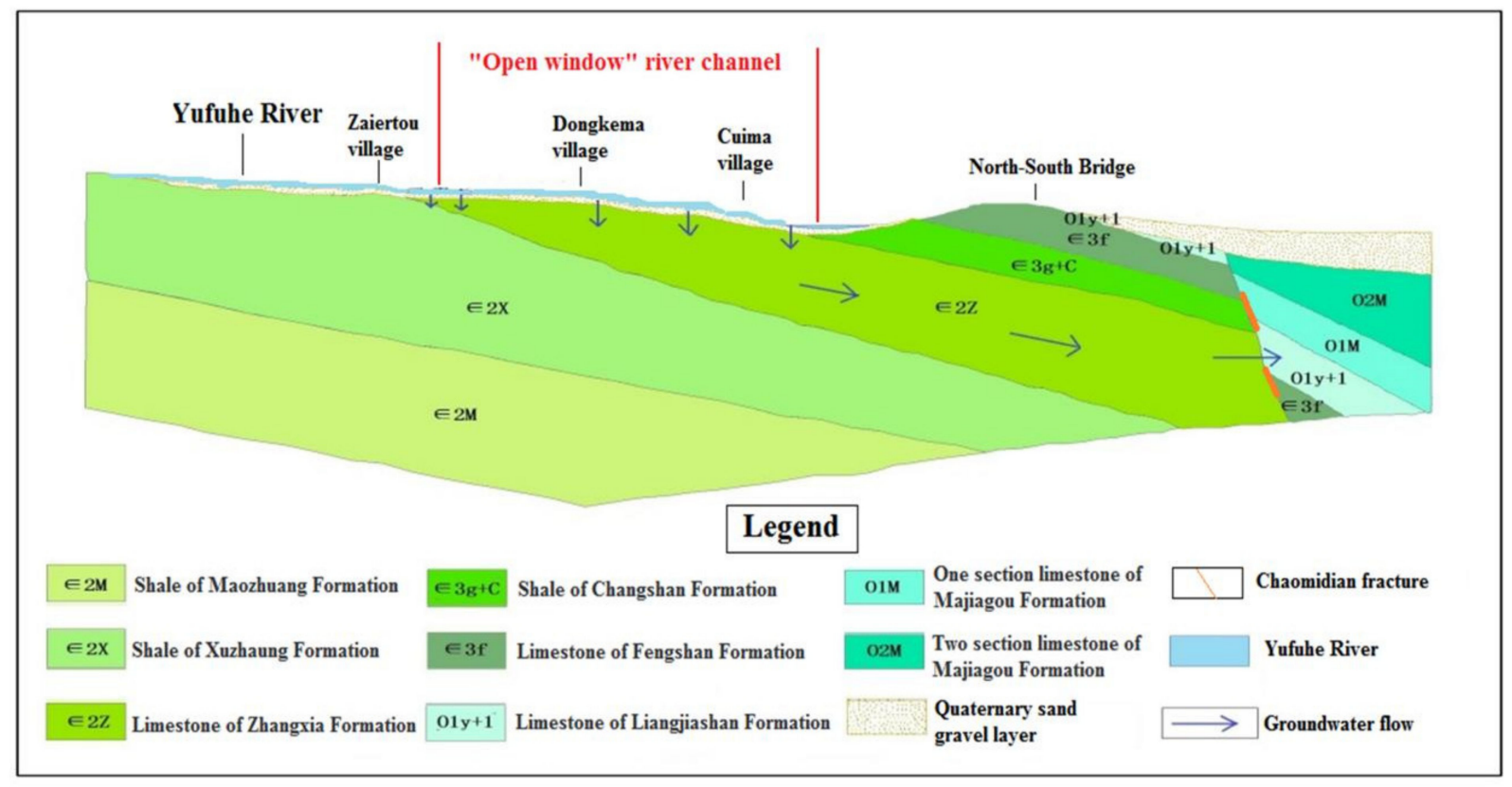

Figure 2. Geological profile of the study area.

The recharge water in the study region is mainly the rainwater flood in the upper reaches of the Wohushan Reservoir and the Yellow River water at the Zaiertou outlet in the upper reaches of the Yufuhe River. Yuqinghu Reservoir is located on the south bank of the Yellow River in Jinan City, adjacent to the Yufuhe River in the northeast. It is connected with the drainage outlet of Zaiertou in the Yufuhe River Basin through pipelines, and the 
Yellow River water is transported to the drainage outlet through the cascade pump station (Figure 1). When the river releases water, a lot of water infiltrates through the reach of the strong seepage zone, and part of the surface water passes through the riverbed, enters the sand and gravel layer, and turns into pore water. The remaining surface water continues to flow downstream due to the large slope of the riverbed. Under the action of gravity, the pore water entering the sand gravel layer continues to leak down and effectively recharges to the karst aquifer. The remaining pore water flows downstream in the form of lateral pore runoff due to the force distribution of gravity in the surface direction. As there is impermeable shale under the sand gravel layer in the downstream of the strong seepage zone, the pore water flowing to the downstream cannot enter the karst aquifer, which is invalid recharge.

\subsection{Materials}

A plexiglass tank with a length, width, and height of 50,10 , and $50 \mathrm{~cm}$, respectively, was used in the experiment (Figure 3). An inflow hole was set at the top of the right side of the sand tank. Three outflow holes were added from top to bottom on the left side of the sand tank to simulate the runoff process of surface, pore, and karst water, respectively. Pressure-measuring holes were installed at the back of the sand groove, and upper and lower spacings of the hole were $15 \mathrm{~cm}$ whilst left and right spacings were $10 \mathrm{~cm}$. All outlet holes were covered with nylon mesh with a diameter of $200(74 \mu \mathrm{m})$. The height of the sand filling area was $50 \mathrm{~cm}$, and the supporting layer with a thickness of $5 \mathrm{~cm}$ was below the sand filling area. The dotted line on the left was a permeable partition with a thickness, hole diameter, and hole spacing of 8,6 , and $10 \mathrm{~mm}$, respectively. The medium filling area was divided into two parts from top to bottom, with a thickness of 30 and $20 \mathrm{~cm}$ for the upper and lower layers, respectively.

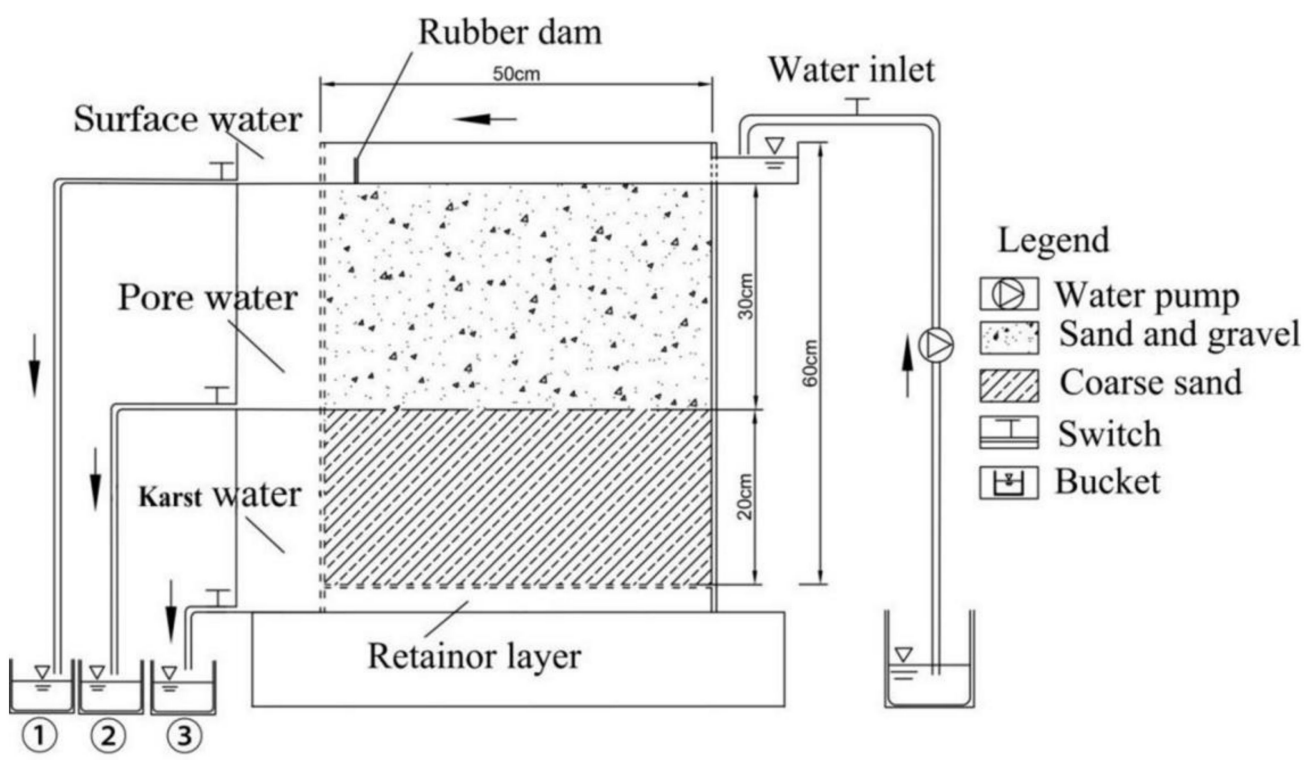

Figure 3. Diagram of the experimental device.

The main components of sediment in the Yellow River are montmorillonite, illite, and chlorite. Montmorillonite accounted for the largest proportion, up to $45 \%$. The diameter of montmorillonite is between 0.2 and $1 \mu \mathrm{m}$. In order to effectively simulate the characteristics of sediment in Yellow River water, nanoscale montmorillonite was used to configure suspension in the sand tank experiment. As the karst aquifer belongs to the complex aquifer system, it contains a variety of medium forms, such as pores, fissures, small karst holes, etc. It is difficult to directly simulate water flow in a fissure karst pipeline under laboratory conditions. Hence, in previous studies, researchers used sand, glass balls, broken sandstone, plexiglass sheets, and other media to simulate karst pipelines [11-13]. In this 
paper, the upper layer of the sand tank was filled with sand and gravel, and the lower layer was filled with coarse sand. The coarse sand was used to simulate Zhangxia limestone, and its permeability was consistent with Zhangxia limestone. The filling medium of the sand tank was obtained from the surface sand sample in the strong leakage area of the Yufuhe riverbed. The grain size distribution demonstrated an effective granularity $\left(\mathrm{d}_{10}\right)$, average granularity $\left(\mathrm{d}_{50}\right)$, and porosity of $0.2 \mathrm{~mm}, 8 \mathrm{~mm}$, and $23.9 \%$, respectively, after the collected sand samples were passed through the sieve. Table 1 lists the relevant characteristics of the filling medium.

Table 1. Parameters of sand tank media.

\begin{tabular}{cccccccc}
\hline $\begin{array}{c}\text { Clay } \\
(\%)\end{array}$ & Porosity (\%) & $\begin{array}{c}\text { Sand and Gravel } \\
(\mathbf{m} / \mathbf{d})\end{array}$ & $\begin{array}{c}\text { Coarse Sand } \\
(\mathbf{m} / \mathbf{d})\end{array}$ & $\begin{array}{c}\mathrm{d}_{\mathbf{1 0}} \\
(\mathbf{m m})\end{array}$ & $\begin{array}{c}\mathbf{d}_{\mathbf{5 0}} \\
(\mathbf{m m})\end{array}$ & $\begin{array}{c}\mathrm{d}_{\mathbf{6 0}} \\
(\mathbf{m m})\end{array}$ & $\begin{array}{c}\mathbf{d}_{\mathbf{6 0}} / \mathbf{d}_{\mathbf{1 0}} \\
13\end{array}$ \\
\hline 13.9 & 90 & 18 & 0.2 & 8 & 12 & 60 \\
\hline
\end{tabular}

The experimental tools used were water pump, two large buckets, several silicone pipes, and an oven. A Hach turbidimeter (TL 2300), laser particle size meter (Beckman Coulter LS 13 320, Brea, CA, USA), and particle counter (IBR) were the experimental equipment in the study.

\subsection{Methods}

A control variable method was used to analyse the mechanism of water distribution and sediment clogging during the water release period of the Yufuhe River. Tests were subjected to both saturated and steady-state flow regimes at three suspended solid concentrations and three different discharge flows. Meanwhile, a two-dimensional saturatedunsaturated steady flow numerical model was established using HYDRUS-2D software to confirm the rationality of the sand tank experimental results and verify the measured results of the laboratory water quantity experiment. In addition, the influence of a rubber dam on water distribution and sediment blockage mechanism was explored to consider the possibility of building a rubber dam.

\subsubsection{Experiment on Water Distribution Mechanism}

(1) The sand tank was filled with the medium, and comparative experiments with a constant flow of $2.5,3$, and $3.5 \mathrm{~L} / \mathrm{min}$ were conducted. Tap water was injected via the water pump from the upper right inlet of the sand tank. The flow rate of each outlet hole was monitored every $10 \mathrm{~min}$, and the water head height of the pressure measuring pipe was recorded. The experiment was stopped when the flow rate of each outlet was stable.

(2) A $3 \mathrm{~cm}$ high rubber dam was installed on the surface of the sand tank to simulate the process of surface water interception. Step (1) was repeated to observe the effect of the rubber dam on the effective infiltration and blockage degree of the riverbed.

(3) A two-dimensional saturated-unsaturated steady-state flow numerical model was established using HYDRUS-2D software to describe the movement law of the water flow in the medium during the recharge period of the Yufuhe River further and verify the measured results of the water quantity experiment. The comparison of the results of the numerical and physical models verified the rationality of using the two-dimensional sand tank to investigate the water distribution mechanism in the recharge process of the piedmont channel.

The hydrogeological conceptual model was established according to parameters of the physical model, such as source, sink term, size, and flow (Figure 4). The model demonstrated a saturated-unsaturated Darcy flow state. The influence of air on the soil flow movement was ignored, and the modified Richards equation was adopted as the governing equation of the water flow (Equations (1)-(6)).

$$
\frac{\partial \theta(h)}{\partial t}=\frac{\partial \theta}{\partial x_{i}}\left[K(h)\left(K_{i j}^{A} \frac{\partial h}{\partial x_{i}}+K_{i z}^{A}\right)\right]-s^{\psi}(h),
$$




$$
\begin{gathered}
h(x, z, t)=h_{0}(x, z),(0 \leq x \leq X, 0 \leq z \leq Z, t=0), \\
{\left[-K(h) \frac{\partial h(x, z, t)}{\partial z} \pm K(h)\right]_{B C}=f(h, t), t \geq 0,} \\
{\left[-K(h) \frac{\partial h(x, z, t)}{\partial z} \pm K(h)\right]_{A D}=0, t \geq 0,} \\
{\left[-K(h) \frac{\partial h(x, z, t)}{\partial z} \pm K(h)\right]_{A B}=0, t \geq 0,} \\
\frac{\partial h}{\partial x}=0, \frac{\partial h}{\partial z}=0,(0 \leq x \leq 50,0 \leq z \leq 50),
\end{gathered}
$$

where $h$ is the pressure head, $\mathrm{cm} ; \theta$ is the volumetric water content, $\mathrm{cm}^{3} / \mathrm{cm}^{3} ; K_{i j}^{A}$ is the dimensionless anisotropic tensor; $K(h)$ is the permeability under pressure head; $s^{\psi}(h)$ is the source sink term; $X$ and $Y$ are the horizontal and vertical maximum lengths of simulated regions, respectively, and $h_{0}(x, y)$ is the initial pressure head.

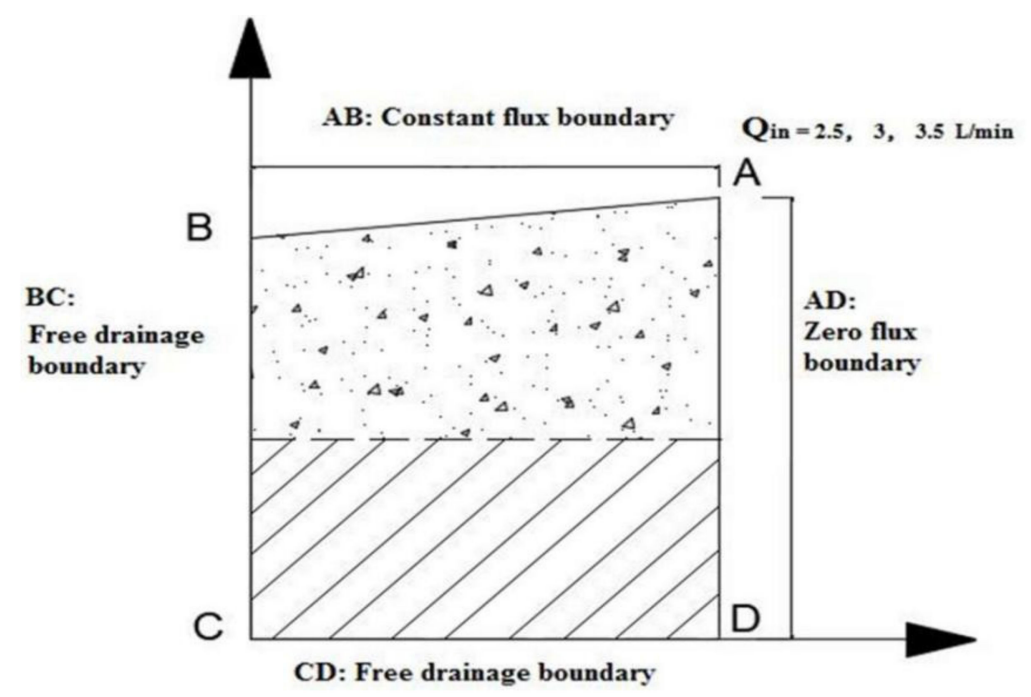

Figure 4. Conceptual model of hydrogeology.

Furthermore, the parameters of the model also need to be set. The initial time, cut-off time, initial time step, minimum time step and maximum time step of the numerical model are 0 and $120 \mathrm{~min}$ and $0.01 \mathrm{~s}, 0.001 \mathrm{~s}$, and $1 \mathrm{~s}$, respectively. The numerical simulation part of this paper is based on the physical model. In addition to Ks, the values of $\theta \mathrm{r}, \theta \mathrm{s} \alpha, \mathrm{n}$, and 1 are selected from the built-in parameters of HYDROUS-2D. HYDROUS-2D software provides a large number of characteristic parameters of dielectric materials. However, the Ks is the actual measured value of sand samples under laboratory conditions (Table 1). The permeability coefficient of coarse sand is consistent with the permeability coefficient of Zhangxia limestone measured in the pumping test, so coarse sand is used instead of limestone. Model soil was generalised into two types. Soil parameters in the study area are listed in Table 2.

$\theta \mathrm{r}, \theta \mathrm{s}$, and Ks represent the saturated water capacity, residual water rate, and hydraulic conductivity, respectively, and $\alpha, \mathrm{n}$, and $\mathrm{l}$ are empirical coefficients.

\subsubsection{Experiment on the Silt Clogging Mechanism}

(1) The sand tank was filled with the medium, and the montmorillonite suspension was used as the recharge water for simulating the Yellow River water. The flow rate into the sand tank was controlled by the water pump at $3 \mathrm{~L} / \mathrm{min}$. Suspensions of 100 , 150, and 200 NTU were injected into the sand tank. The recharge water was changed to tap water after the suspension was supplied for $160 \mathrm{~min}$. The flow rate and turbidity of 
each outlet were monitored every $10 \mathrm{~min}$ whilst recording the water head height of the pressure-measuring pipe during the test. The test was stopped when the flow rate of each outlet was stable. The sand column was dismantled and the sand sample was dried and weighed after the test. The montmorillonite in the sand sample was then washed with water, and the sand sample was dried and weighed again. The difference in mass between the two measurements indicated the deposition mass of fine particles in the sand tank.

(2) A $3 \mathrm{~cm}$ high rubber dam was set up on the surface of the sand tank to simulate the process of building the rubber dam and storing surface water in the river channel. Step (1) was repeated to examine the influence of the presence of the rubber dam on the effective infiltration and blockage of the river channel.

Table 2. Soil parameters of the model.

\begin{tabular}{cccccccc}
\hline \multirow{2}{*}{ Lithology } & \multirow{2}{*}{$\begin{array}{c}\text { Thickness } \\
\mathbf{( c m )}\end{array}$} & \multicolumn{5}{c}{ Parameter } \\
\cline { 3 - 8 } & & $\theta \mathbf{r}$ & $\theta \mathbf{s}$ & $\boldsymbol{\alpha}$ & $\mathbf{n}$ & $\mathbf{K s ~ ( c m / s ) ~}$ & $\mathbf{1}$ \\
\hline Sand-gravel layer & 30 & 0.045 & 0.43 & 0.145 & 2.68 & 0.104 & 0.5 \\
Cambrian Zhangxia formation limestone & 20 & 0.057 & 0.41 & 0.124 & 2.28 & 0.021 & 0.5 \\
\hline
\end{tabular}

\section{Results}

\subsection{Water Distribution Mechanism}

\subsubsection{Influence of the Water Release Rate}

Water released during the entire experiment was divided into karst, pore, and surface water (Figure 5). Water accumulated at the interface of the two media and resulted in horizontal and straight runoffs (lateral pore and karst runoffs) because the upper medium was the sand and gravel layer with strong permeability and the lower layer was the coarse sand with weak permeability.

Karst, surface, and pore runoff values were 1.67-1.7, 0.36-1.26, and 0.36-0.54 L/min, respectively, after the experiment reached the stable state (Table 3). The proportion of karst water to recharge water was approximately $60-70 \%$. The change of the karst water was not obvious with the increase in water release flow. By comparison, the surface and pore water increased rapidly (Figure 5a,c,e). The remaining water released was mainly converted into surface and pore runoffs to the downstream channel after the karst runoff reached the critical value. These two parts of the water were not actually recharged to the karst aquifer and were invalid recharges. Therefore, a reasonable released water plan should be developed to ensure the effective recharge of the karst aquifer.

Table 3. Experimental results of the water quantity.

\begin{tabular}{|c|c|c|c|c|c|}
\hline $\begin{array}{c}\text { Serial } \\
\text { Number }\end{array}$ & Rubber Dam & $\begin{array}{l}\text { Released Water } \\
\text { (L/min) }\end{array}$ & $\begin{array}{l}\text { Karst Water } \\
\text { (L/min) }\end{array}$ & $\begin{array}{l}\text { Surface Water } \\
\quad(\mathrm{L} / \mathrm{min})\end{array}$ & $\begin{array}{l}\text { Pore Water } \\
\text { (L/min) }\end{array}$ \\
\hline (1) & \multirow{3}{*}{ No } & 2.5 & 1.67 & 0.36 & 0.47 \\
\hline (2) & & 3 & 1.68 & 0.96 & 0.36 \\
\hline (3) & & 3.5 & 1.7 & 1.26 & 0.54 \\
\hline (4) & \multirow{3}{*}{ Yes } & 2.5 & 1.72 & 0.3 & 0.48 \\
\hline (5) & & 3 & 1.78 & 0.62 & 0.6 \\
\hline (6) & & 3.5 & 1.75 & 1.22 & 0.53 \\
\hline
\end{tabular}

Note: Flow values in Table 3 represent the measured values of each outlet hole during the steady state of the experiment.

\subsubsection{Influence of the Rubber Dam}

The construction of the rubber dam on the surface of the river channel demonstrated a positive effect on increasing the karst water. The karst runoff rate of the experimental group with the rubber dam was $1.72-1.78 \mathrm{~L} / \mathrm{min}$, which was significantly higher than that of the experimental group without the rubber dam at 1.67-1.7 L/min (Table 3). 
The rubber dam promoted the conversion of surface runoff to pore runoff. Due to the large slope of the channel, the water released rapidly flowed to the downstream in the form of surface runoff. Surface runoff with high velocity can be transformed into pore runoff with low velocity by setting the rubber dam to achieve the effect of retaining surface water (Table 3).

(a)

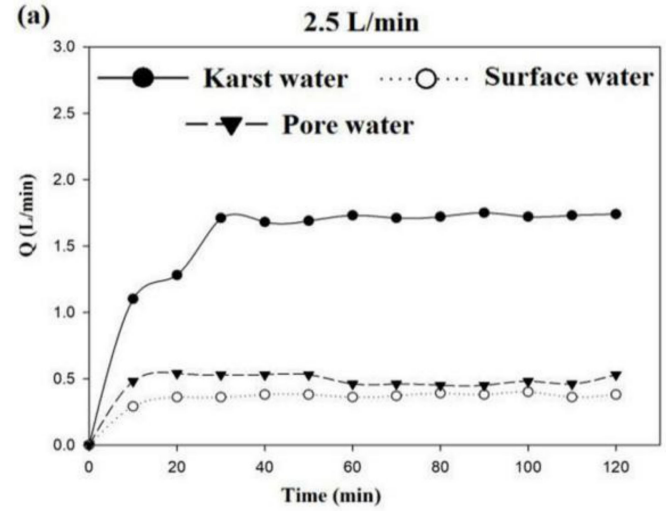

(c)

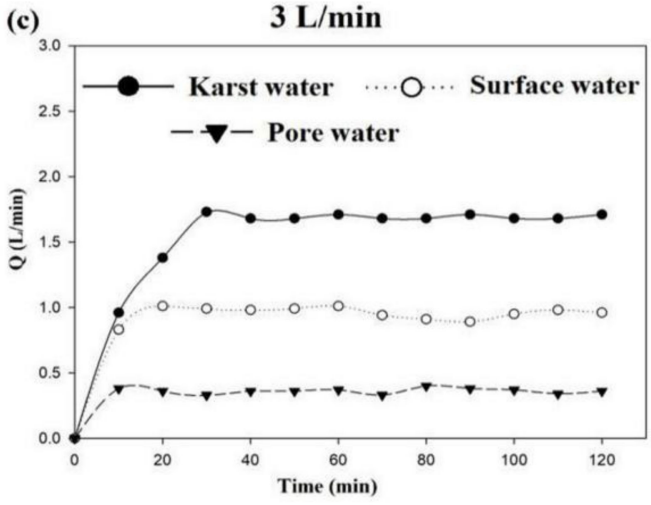

(e)

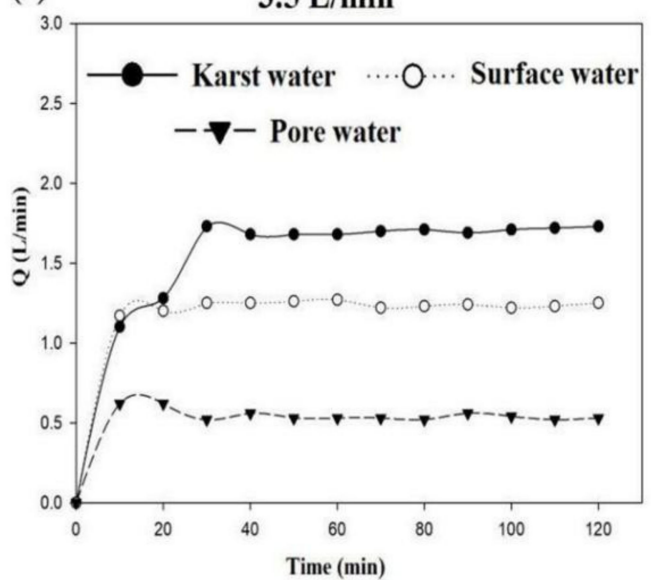

(b)

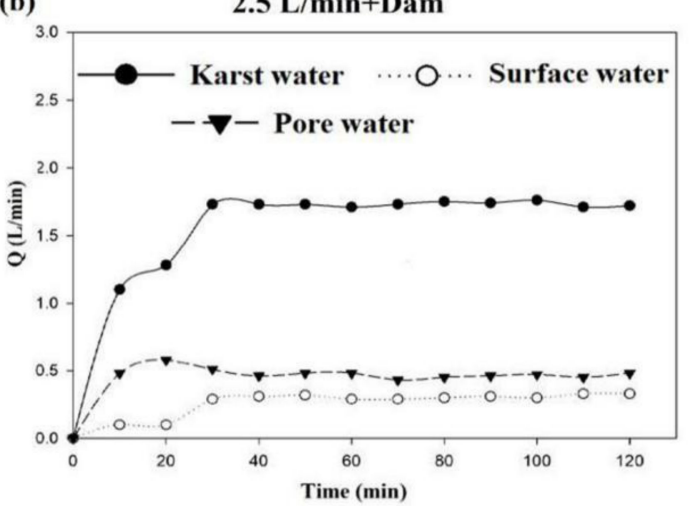

(d)

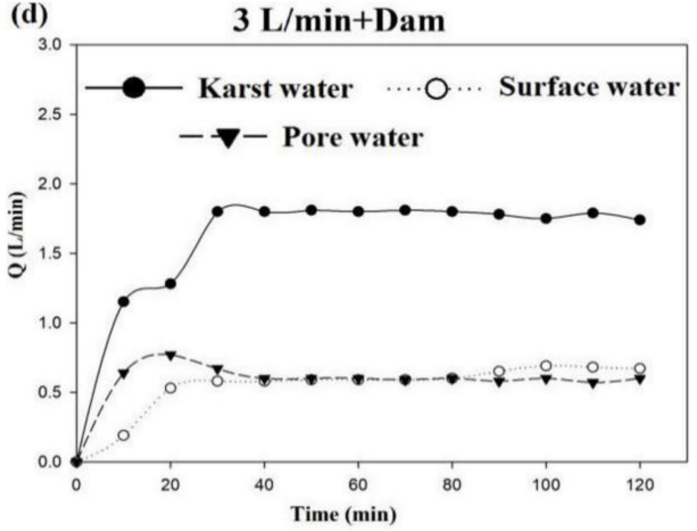

(f)

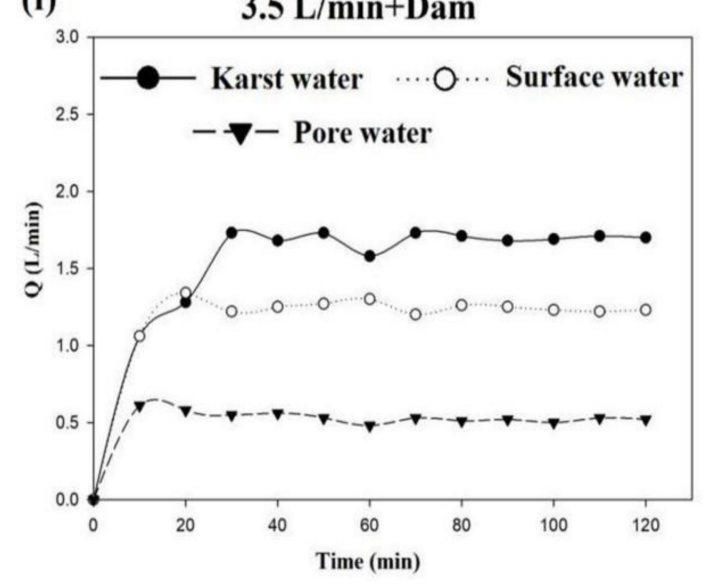

Figure 5. (a,c,e) Flow curves of surface water, pore water, and karst water when the river water release rate is $2.5,3$, and $3.5 \mathrm{~L} / \mathrm{min}$, respectively. $(\mathbf{b}, \mathbf{d}, \mathbf{f})$ Flow curves of surface water, pore water, and karst water when the river water release rate is $2.5,3$, and $3.5 \mathrm{~L} / \mathrm{min}$, respectively, after the rubber dam is built in the riverbed.

\subsubsection{Influence of Suspended Particles}

The concentration of suspended particles in the recharge water also affected the runoff distribution in the medium. Karst and pore runoffs decreased whilst the surface runoff 
increased with the increase in turbidity in the released water (Figure 6). Compared with tap water, the karst runoff decreased by $36.9 \%, 66.7 \%$, and $66.7 \%$ when the turbidity was 100 , 150, and 200 NTU, respectively (Table 4). The permeability of the medium was reduced rapidly and the seepage of river channel to recharge groundwater was interrupted because the pore space of the medium was occupied by suspended particles in the recharge water. Lastly, the riverbed was clogged.

(a)

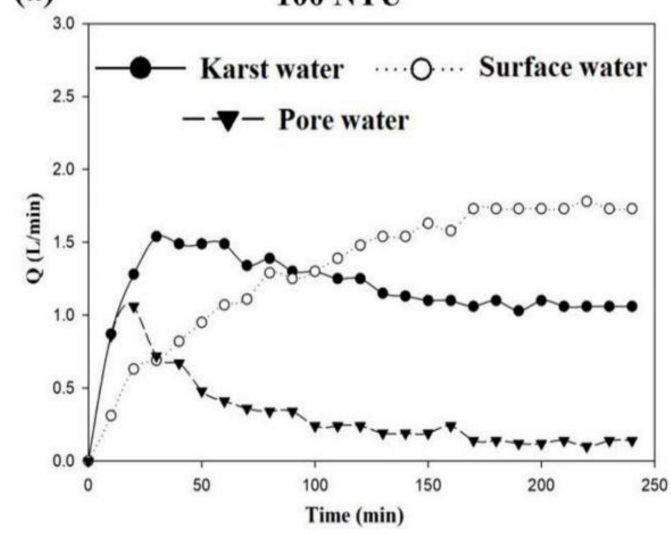

(c)

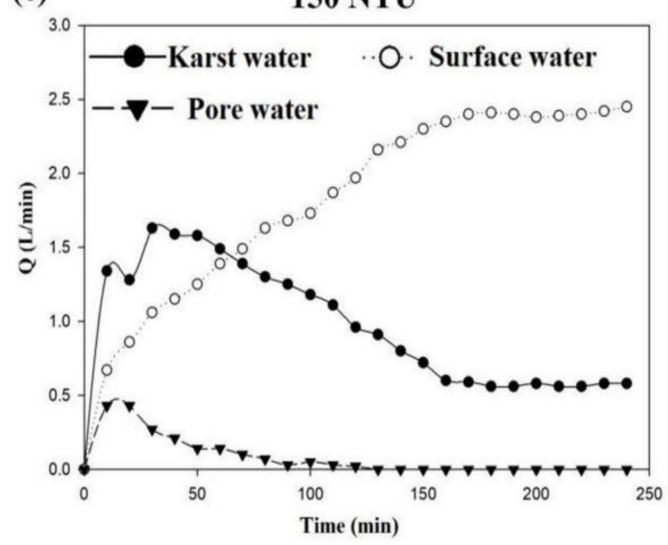

(e)

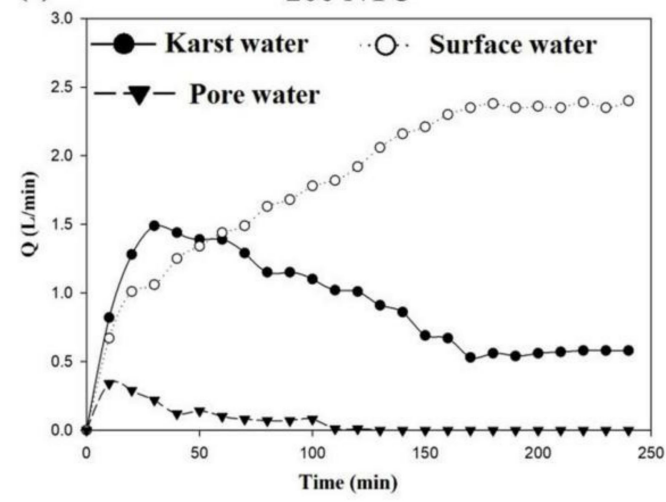

(b)

100 NTU+Dam

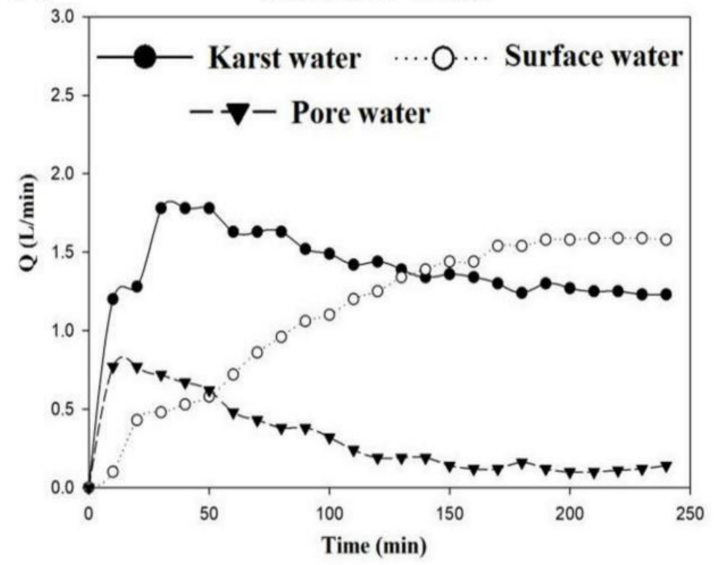

(d) 150 NTU+Dam

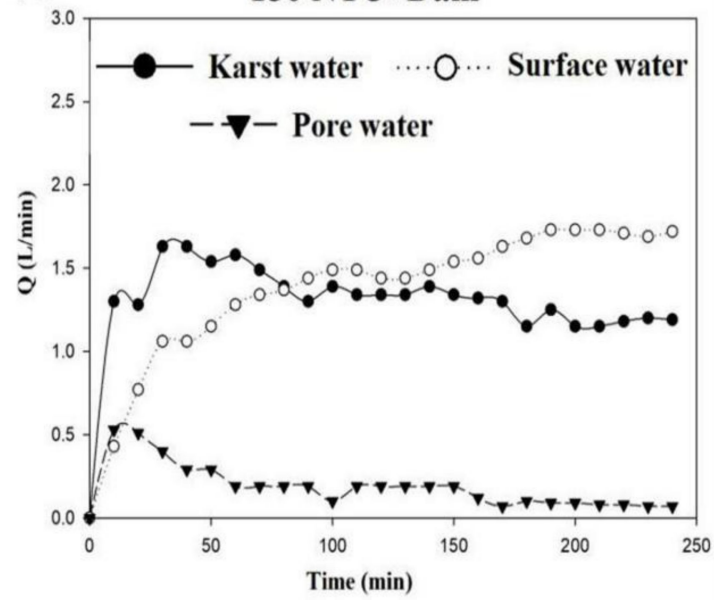

(f)

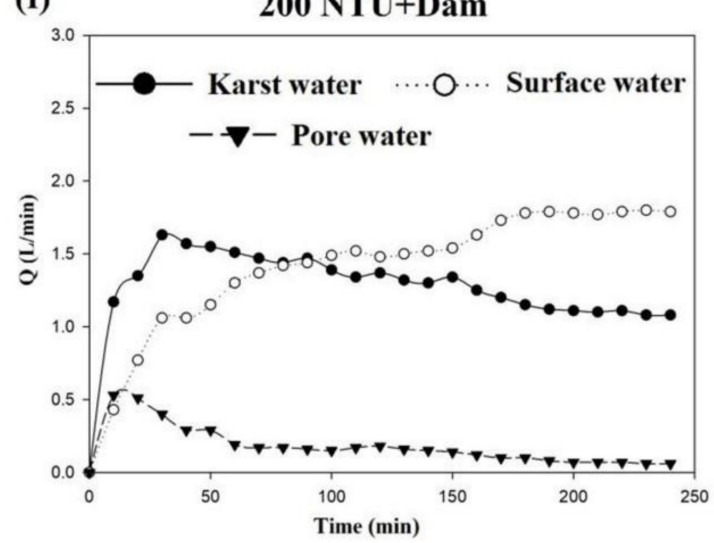

Figure 6. (a,c,e) Flow curves of surface water, pore water, and karst water when the turbidity of recharge water is 100, 150, and 200 NTU, respectively. (b,d,f) Flow curves of surface water, pore water, and karst water when the turbidity of recharge water is 100, 150, and 200 NTU, respectively, after the rubber dam is built in the riverbed. 
Table 4. Experimental results of suspended particles.

\begin{tabular}{cccccc}
\hline $\begin{array}{c}\text { Serial } \\
\text { Number }\end{array}$ & $\begin{array}{c}\text { Rubber } \\
\text { Dam }\end{array}$ & $\begin{array}{c}\text { Turbidity } \\
\text { (NTU) }\end{array}$ & $\begin{array}{c}\text { Karst Water } \\
\text { (L/min) }\end{array}$ & $\begin{array}{c}\text { Surface Water } \\
\text { (L/min) }\end{array}$ & $\begin{array}{c}\text { Pore Water } \\
\text { (L/min) }\end{array}$ \\
\hline (1) & & 100 & 1.06 & 1.81 & 0.13 \\
$(2)$ & No & 150 & 0.56 & 2.44 & 0 \\
(3) & & 200 & 0.56 & 2.44 & 0 \\
\hline (4) & & 100 & 1.26 & 1.61 & 0.13 \\
$(5)$ & Yes & 150 & 1.2 & 1.72 & 0.08 \\
(6) & & 200 & 1.14 & 1.79 & 0.07 \\
\hline
\end{tabular}

Note: Flow values in Table 4 represent the measured values of each outlet hole during the steady state of the experiment.

\subsection{Numerical Simulation Verification of the Water Quantity Experiment}

Increasing the discharge flow insignificantly affects the change of the water head, and most of the remaining water flowed downstream in the form of surface runoff due to the influence of slope and infiltration capacity. Therefore, the test with a flow of $3 \mathrm{~L} / \mathrm{min}$ was selected for simulation. The pressure head was interpolated linearly according to the buried depth, and the pressure head increased gradually with the experiment (Figure 7). The sand tank reached the stable state at $15 \mathrm{~min}$. The simulation results showed that the upper medium is sand and gravel with strong permeability and the lower layer is coarse sand with weak permeability. Water will form at the interface of the medium and result in a lateral runoff with the increase in recharge time. Moreover, the fitting degree of the water level with time is better, with a correlation coefficient above 0.9 , when the results of the numerical model and experimental monitoring are compared (Figure 8).

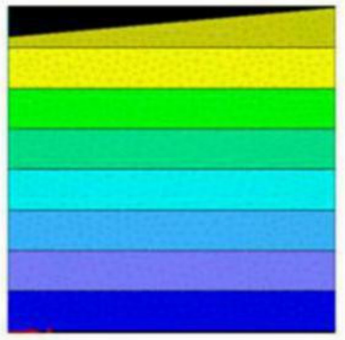

$0 \mathrm{~min}$

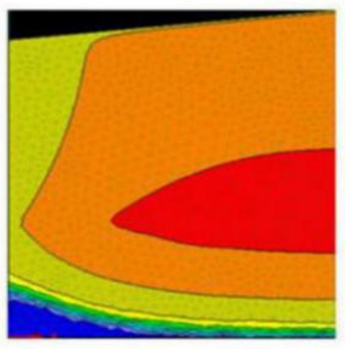

$10 \mathrm{~min}$

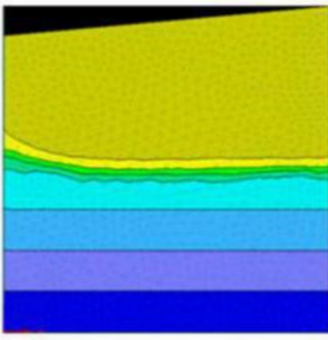

$3 \mathrm{~min}$

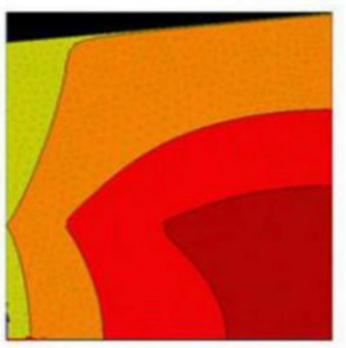

$15 \min$

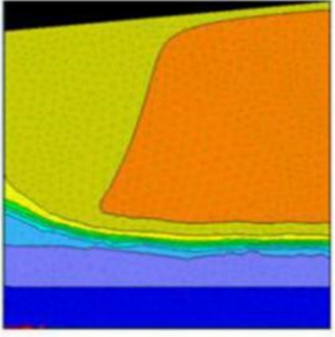

$6 \mathrm{~min}$

Legend

Head $(\mathrm{cm})$

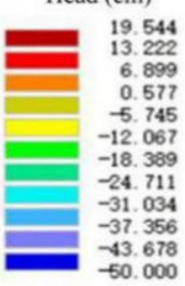

Figure 7. Simulation results of the water quantity experiment.

\subsection{Suspended Particle Clogging Mechanism}

\subsubsection{Changes in Turbidity}

The turbidity of the surface water was nearly equal to that of the reinjection water during the experiment (Figure 9). The turbidity of the karst water was between 0 and 3 NTU, whilst that of pore water was between 0 and 8 NTU. The medium reduced the turbidity of the karst and pore water by more than $96 \%$. The decrease in turbidity in recharge water also reflected the degree of blocking of suspended particles in the sand tank. The time at which the intersection of surface and karst runoff velocities occurred 
demonstrated whether the clogging time moved forward. High turbidity of the recharge water indicated the early occurrence of blockage (Figure 6).

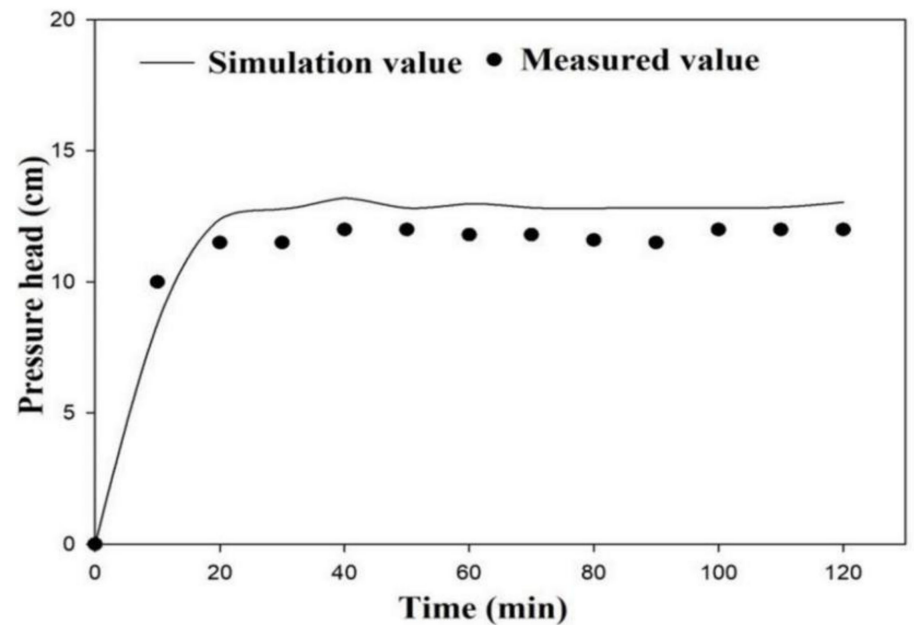

Figure 8. Fitting curve between measured and simulated values.

The decrease in the medium permeability mainly depended on the concentration of suspended particles in the recharge water. The ratio of the karst runoff $Q$ in the suspended particle experiment to the karst runoff $\mathrm{Q}_{0}$ corresponding to $3 \mathrm{~min} / \mathrm{L}$ in the water quantity experiment was used to reflect the clogging rate of the medium. The karst water runoff corresponding to the turbidity of the recharge water at 100, 150, and 200 NTU was reduced to $63 \%, 33 \%$, and $33 \%$, respectively, compared with that at turbidity of recharge water of 0 NTU, after the experiment (Figure 10a).

\subsubsection{Influence of the Rubber Dam}

The construction of the rubber dam on the surface of the river channel caused insignificant changes in the turbidity of karst and pore water (Figure 6). In addition, the advance of plugging time of the sand tank was unaffected by the construction of the rubber dam (Figure 6).

The existence of the rubber dam increased not only the karst runoff but also the retention of suspended particles in the sand tank (Figure 10a,b and Table 5). The mass of suspended particles increased by $15.1-25.4 \%$ due to the rubber dam. Conversely, the suspended particles in the surface runoff was reduced by approximately $20 \%$. The suspended solid was also intercepted and followed the water flow into the porous medium in the process of retaining surface water by the rubber dam. Therefore, the infiltration rate increased with the increase in the blocking degree of the sand tank. The rubber dam was removed and the flow rate was increased to simulate a dam break after the experiment. In this way, the scouring ability of the riverbed surface may be improved and the clogging degree can be alleviated. The test indicated that only the surface layer was washed away and the restoration of the permeability of the medium was not obvious because the blockage of the medium was already formed.

Table 5. Migration of suspended particles.

\begin{tabular}{|c|c|c|c|c|c|c|c|}
\hline $\begin{array}{l}\text { Serial } \\
\text { Number }\end{array}$ & $\begin{array}{l}\text { Rubber } \\
\text { Dam }\end{array}$ & $\begin{array}{l}\text { Turbidity } \\
\text { (NTU) }\end{array}$ & $\begin{array}{c}\text { Total } \\
\text { (g) }\end{array}$ & $\begin{array}{l}\text { Karst Water } \\
\text { (g) }\end{array}$ & $\begin{array}{c}\text { Surface Water } \\
\text { (g) }\end{array}$ & $\begin{array}{l}\text { Pore Water } \\
\text { (g) }\end{array}$ & $\begin{array}{l}\text { Retained } \\
\text { (g) }\end{array}$ \\
\hline (1) & & 100 & 39.8 & 0.8 & 16.3 & 0.2 & 22.5 \\
\hline (2) & $\mathrm{N}$ & 150 & 56.4 & 0.3 & 30.4 & 0.1 & 25.6 \\
\hline (3) & & 200 & 75.2 & 0.2 & 41.4 & 0.03 & 33.57 \\
\hline (4) & & 100 & 39.8 & 0.7 & 13 & 0.2 & 25.9 \\
\hline (5) & Y & 150 & 56.4 & 0.4 & 24.2 & 0.2 & 31.6 \\
\hline (6) & & 200 & 75.2 & 0.4 & 32.5 & 0.2 & 42.1 \\
\hline
\end{tabular}


(a)

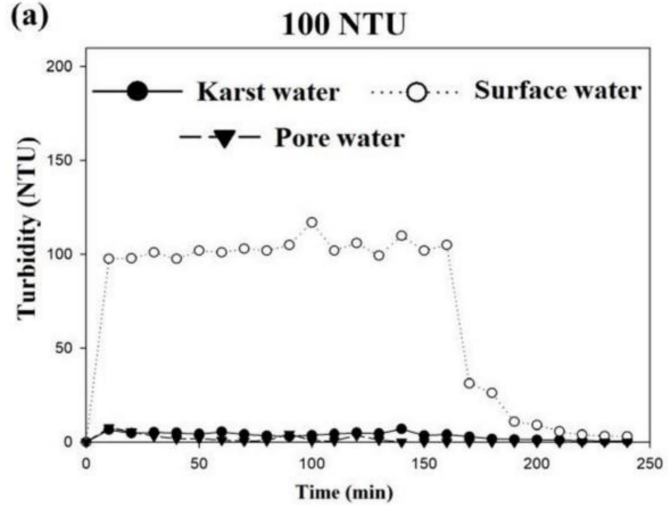

(c)

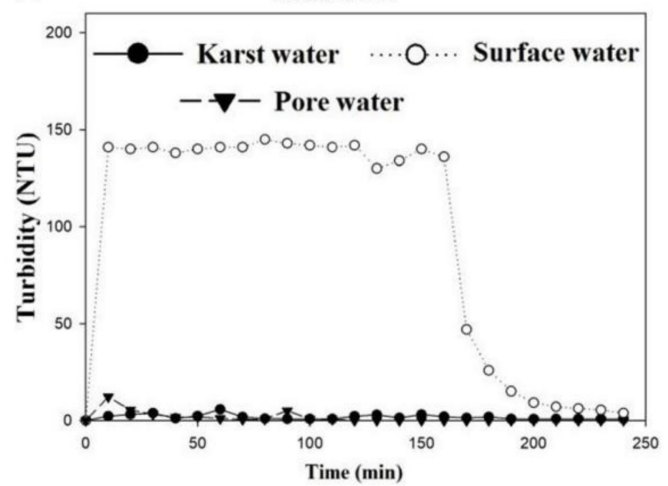

(e)

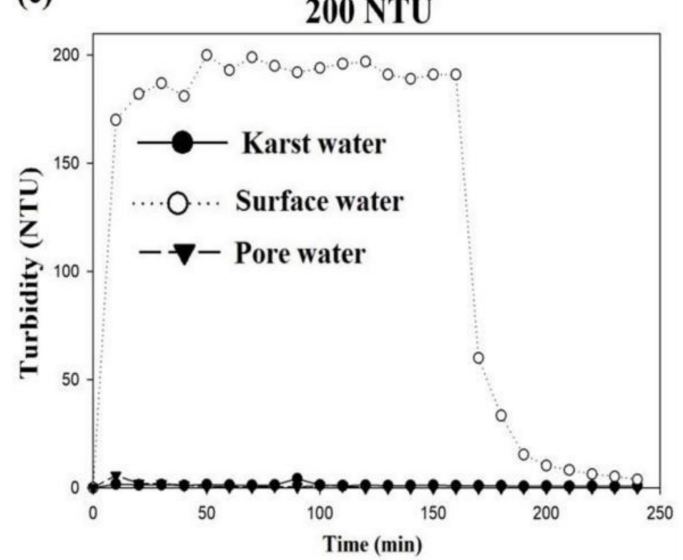

(b)

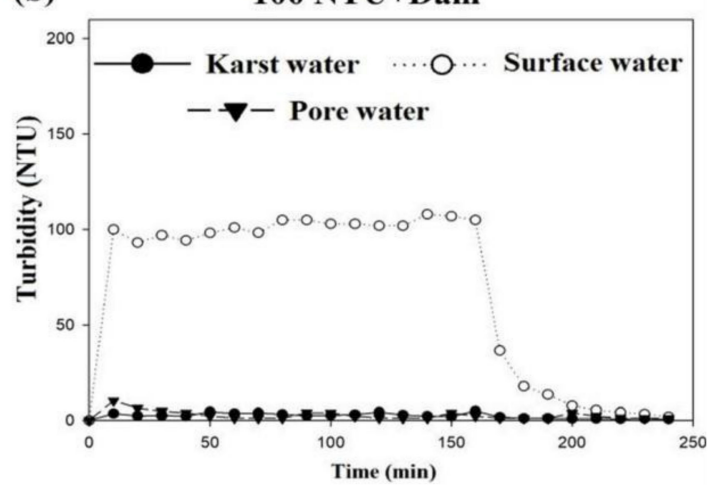

(d)

150 NTU+Dam

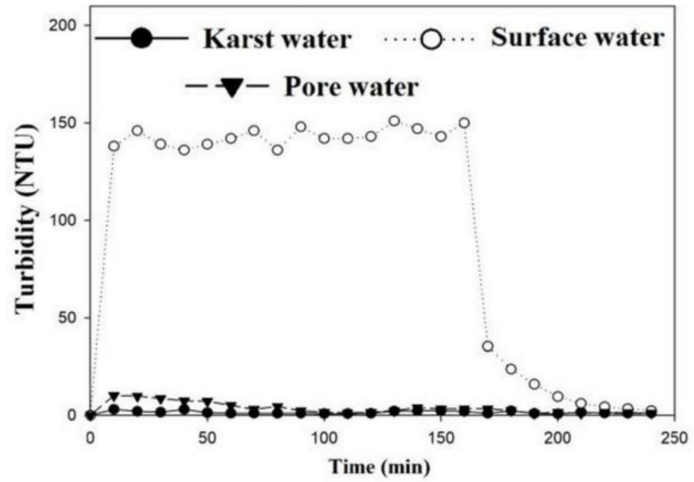

(f)

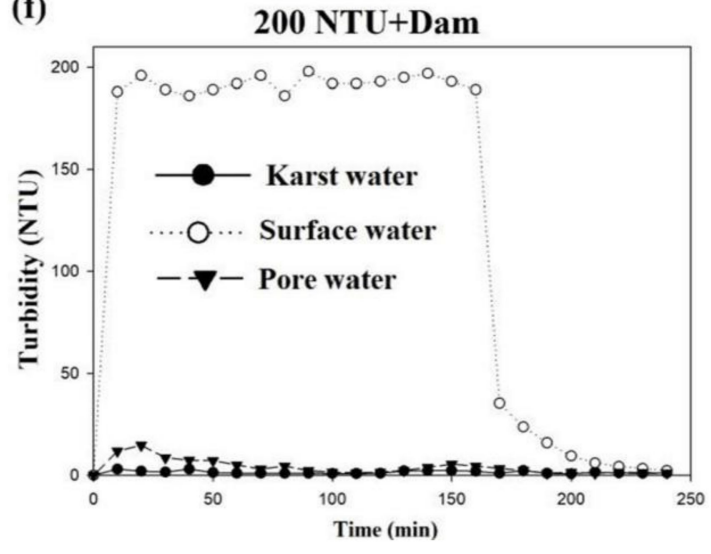

Figure 9. (a,c,e) Turbidity curves of surface water, pore water, and karst water when the turbidity of recharge water is 100 , 150, and 200 NTU, respectively. (b,d,f) Turbidity curves of surface water, pore water, and karst water when the turbidity of recharge water is 100, 150, and 200 NTU, respectively, after the rubber dam is built in the riverbed.

\subsubsection{Migration of Suspended Particles}

The distribution of suspended particles in the sand tank was calculated, that is, the outflow mass of surface, pore, and karst runoffs and retention in the sand tank were calculated as follows:

$$
M=\sum q \times m
$$

where $M$ is the mass of suspended fine particles, $q$ is the flow rate at different times of the inlet or outlet, and $m$ is the concentration of suspended particles in the water converted from turbidity. The calculation results are listed in Table 5. 

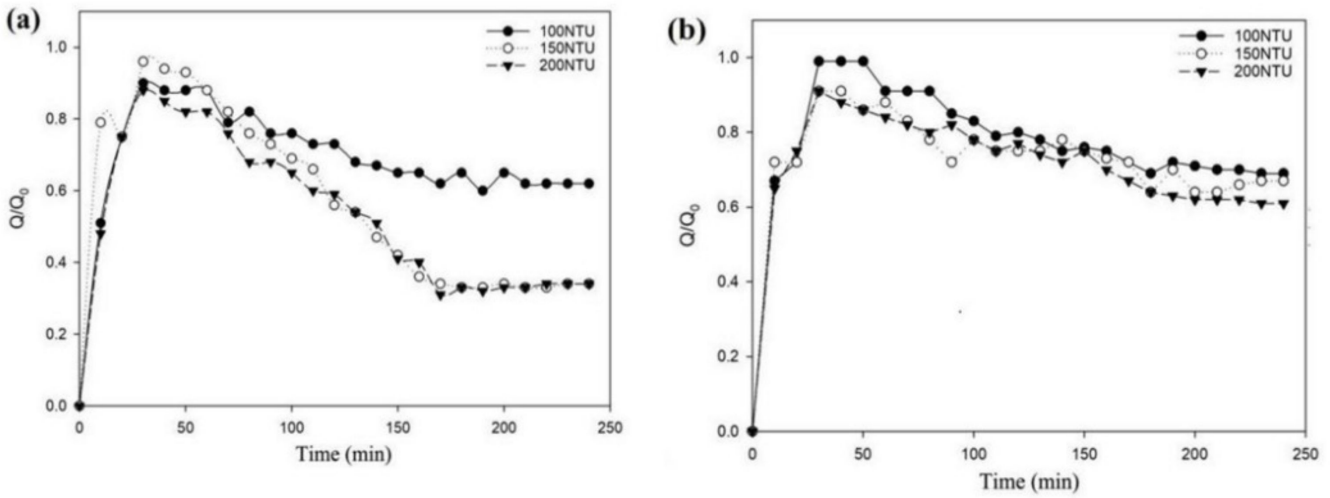

Figure 10. (a) Clogging rate of the medium without the rubber dam. (b) Clogging rate of the medium with the rubber dam.

The high turbidity of the recharge water increased the deposition mass of suspended particles in the sand tank. The deposition mass of suspended particles in the sand tank was $13.8 \%$ and $49.2 \%$ higher than that of $100 \mathrm{NTU}$ when the turbidity of the recharge water was 150 and 200 NTU, respectively. At least $40 \%$ of suspended particles in the recharge water were filtered by the sand tank and another $30 \%$ of suspended particles flowed downstream with the surface runoff (Table 5). Suspended particles in the sand tank were stratified and measured after the experiment. The results showed that the mass of suspended solids was mainly concentrated in the surface and upper areas of the sand tank. A thin layer of clay was observed on the surface of the sand tank. The surface sand sample of the sand tank was washed and backfilled after the suspension test. The water quantity test was carried out again and the karst runoff could be restored to the initial value.

\section{Discussion}

It is a meaningful way to recharge groundwater by river seepage, which can not only increase groundwater quantity, but also improve water quality $[14,15]$. However, due to the different topography and hydrogeological conditions of the river channel, the movement process of groundwater in the recharge process is also very different. In this paper, the released river water is divided into surface water, pore water, and karst water during the recharge of the piedmont channel. The karst water can be truly recharged to the fissure karst aquifer, accounting for $60-70 \%$ of the total released water. Li et al. [1] obtained the same conclusion by means of numerical simulation. Thus, it is necessary to make a reasonable water release plan to ensure effective recharge efficiency. In previous studies, Zheng et al. [7] studied aquifer clogging caused by the Yellow River recharge in the Yufuhe River by a sand column experiment. The results showed that most suspended particles are deposited in the surface layer of the medium, and the permeability coefficient of the surface medium decreases the fastest. Wang et al. [6] think that the probability of surface plugging is the highest. The particles in stormwater can cause the aquifer clogging, and the particles are mainly deposited in the range of $1-2 \mathrm{~cm}$ below the surface of the medium. Similarly, the results of this study show that the suspended particles are mainly deposited on the surface of the sand tank, and the thin clay layer formed by the fine particles deposited on the surface of the sand tank is the main reason for the decrease in infiltration. However, Zheng et al. [7] only carried out sand column experiments under onedimensional conditions, which could not effectively prove the distribution of suspended particles in horizontal and vertical directions during the recharge of the piedmont river channel. The two-dimensional sand tank experiment designed in this paper solves this problem well, in which the turbidity of karst water is 0-3 NTU and that of pore water is 0-8 NTU. The results show that the removal rate of suspended particles is over $96 \%$, and most of them are deposited in the upper layer of the medium, which hinders the migration of suspended particles to the depth of the aquifer. This can effectively protect the water quality of karst water in Jinan City. The results of this paper can provide suggestions for 
the efficient operation of the recharge project and the formulation of a reasonable water release plan in Yufuhe River Basin. The experimental model in this paper can provide a new idea for the study of water distribution and suspended particle blockage during recharge in the piedmont river.

In addition, there are some problems in this paper that need to be improved, and this is also the focus of the next research work. Firstly, the water flow in the medium is a variable saturation process during recharge in practice. The experimental conditions of this study were carried out under the condition of saturated flow. Secondly, the numerical simulation in this study only played the role of auxiliary verification, which aims to verify the rationality of the sand tank model experiment. Notably, COMSOL Multiphysics software will be used to simulate the process of variable saturated flow with variable permeability coefficients numerically under the interaction of water and suspended particles in a future investigation. Finally, the physical clogging of aquifers is the focus of this study, but the influence of microbial life activities on riverbed permeability is ignored. It is one of the further works to investigate the influence of microbial life activities in the pore medium of riverbeds on the permeability of aquifers by means of physical experiments and numerical simulation.

\section{Conclusions}

The experimental study was carried out to solve problems of water distribution and sediment blockage in the recharge process of the piedmont channel. Experimental data of water tests were simulated using HYDRUS-2D software to verify the rationality of experimental results of the sand tank model. Effects of water release rate, a rubber dam, and suspended particles on the water distribution and sediment blockage were fully considered in the experiment. The following conclusions can be drawn from this study:

(1) Infiltration, surface, and lateral groundwater runoffs exist simultaneously and represent karst, surface, and pore water, respectively, in the recharge process. The karst water of the Yufuhe River accounted for $60-70 \%$ of the total recharge amount. A reasonable water release plan is necessary because the remaining released water was considered an invalid recharge when the karst runoff flow reached the critical value. The existence of the rubber dam could increase the karst water amount in a small range whilst demonstrating an evident effect on retaining the surface runoff. The significant influence of suspended particles on water distribution can reduce the infiltration amount by $40-70 \%$.

(2) During groundwater recharge, surface clogging can easily form. Zheng et al. studied the aquifer clogging caused by Yellow River water recharge, and concluded that the mass of suspended particles deposited in the surface layer of the medium was the largest [7]. In the study of sediment blockage and migration, reduced infiltration was primarily caused by the thin clay layer formed by suspended fine particles on the surface layer of the pore medium. Surface sand samples were washed and then backfilled to the sand tank for water quantity experiments after the plugging was formed, and the measured infiltration amount was restored to the initial proportion. The increase in turbidity value promoted the deposition of suspended particles in the sand tank. The turbidity removal rate of lateral and infiltration runoffs was more than $96 \%$. The rubber dam could increase the deposition of suspended particles in the sand tank by 15.1-25.4\%. The upper medium of the strong leakage zone of the Yufuhe River is the sand and gravel layer, and the lower layer is made up of Zhangxia limestone with a weak permeability coefficient that belongs to the combination of "upper coarse and lower fine". The results of clogging tests showed that suspended particles are mainly deposited in the surface and upper layers of the medium. This combination of "upper coarse and lower fine" can effectively prevent the migration of suspended particles to the deep layer and avoid the interference of suspended solids with the karst aquifer.

(3) The numerical model of water tests was established using HYDRUS-2D software, and the correlation coefficient between the simulation and measured results was above 
0.9. Hence, the sand tank model can be used to explore the recharge process of the piedmont channel.

Author Contributions: This paper was a collaboration among all authors. W.W. and S.L. designed the study and helped improve its progression and clarity. W.Z. wrote the paper. S.Q., X.S., and Y.M. helped in revising the paper. All authors have read and agreed to the published version of the manuscript.

Funding: This study was supported by the Danish Development Agency (DANIDA) coordinated by the DANIDA Fellowship Center (DFC) through Grant no.17-M08-GEU and Shandong Provincial Key Research and Development Project (2017GSF17121).

Institutional Review Board Statement: Not applicable.

Informed Consent Statement: Not applicable.

Data Availability Statement: Data sharing is not applicable to this article.

Conflicts of Interest: The authors declare no conflict of interest. The funders had no role in the design of the study; in the collection, analyses, or interpretation of data; in the writing of the manuscript, or in the decision to publish the results.

\section{References}

1. Li, W.; Sun, Q.; Wang, W.; Qu, S.; Zhang, Z.; Xu, Q. Effective water quantity of multi-source water recharging aquifers in Yufuhe River based on groundwater and surface water semi-coupled modeling. Water Supply 2019, 19, 2280-2287. [CrossRef]

2. Dillon, P. Future management of aquifer recharge. Hydrogeol. J. 2005, l3, 313-316. [CrossRef]

3. Tielemans, M.W.M. Artificial recharge of groundwater in The Netherlands. Water Pract. Technol. 2007, 2. [CrossRef]

4. Ross, A. Speeding the transition towards conjunctive water management in Australia. J. Hydrol. 2018, 567, e1-e10. [CrossRef]

5. Wang, Y.; Huo, M.; Li, Q.; Fan, W.; Yang, J.; Cui, X. Comparison of clogging induced by organic and inorganic suspended particles in a porous medium: Implications for choosing physical clogging indicators. J. Soil Sediment 2018, 18, 2980-2994. [CrossRef]

6. Wang, Z.; Du, X.; Yang, Y.; Ye, X. Surface clogging process modeling of suspended solids during urban stormwater aquifer recharge. J. Environ. Sci. 2012, 24, 1418-1424. [CrossRef]

7. Zheng, Q.; Wang, W.; Liu, S.; Qu, S. Physical clogging experiment of sand gravel infiltration with Yellow River water in the Yufuhe River channel of Jinan, China. Front. Earth Sci. 2020, 14, 306-314. [CrossRef]

8. Xie, Y.; Wang, Y.; Huo, M.; Geng, Z.; Fan, W. Risk of physical clogging induced by low-density suspended particles during managed aquifer recharge with reclaimed water: Evidences from laboratory experiments and numerical modeling. Environ. Res. 2020, 186, 109527. [CrossRef] [PubMed]

9. Ahfir, N.D.; Wang, H.; Benamar, A.; Alem, A.; Massei, N.; Dupont, J.-P. Transport and deposition of suspended particles in saturated porous media: Hydrodynamic effect. Hydrogeol. J. 2007, 15, 659-668. [CrossRef]

10. Siriwardene, N.R.; Deletic, A.; Fletcher, T.D. Clogging of stormwater gravel infiltration systems and filters: Insights from a laboratory study. Water Res. 2007, 41, 1433-1440. [CrossRef] [PubMed]

11. Soni, J.P.; Islam, N.; Basak, P. Experimental evaluation of non-Darcian flow in porous media. J. Hydrol. 1978, 38, $231-241$. [CrossRef]

12. Huang, X.; Tang, P.; Miao, X.; Chen, Z.Q. Testing study on seepage properties of broken sandstone. Rock Soil Mech. 2005, 26, 1385-1388. [CrossRef]

13. Liu, L.; Shu, L.; Chen, X.; Oromo, T. The Hydrologic Function and Behavior of the Houzhai Underground River Basin, Guizhou Province, Southwester China. Hydrogeol. J. 2010, 18, 509-518. [CrossRef]

14. Cartwright, I.; Irivine, D. The spatial extent and timescales of bank infiltration and return flows in an upland river system: Implications for water quality and volumes. Sci. Total Environ. 2020, 743, 140748. [CrossRef] [PubMed]

15. Bertelkamp, C.; Van Der Hoek, J.; Schoutteten, K.; Hulpiau, L.; Vanhaecke, L.; Bussche, J.V.; Cabo, A.; Callewaert, C.; Boon, N.; Löwenberg, J.; et al. The effect of feed water dissolved organic carbon concentration and composition on organic micropollutant removal and microbial diversity in soil columns simulating river bank filtration. Chemosphere 2016, 144, 932-939. [CrossRef] [PubMed] 